\title{
Expression and prognostic analyses of ITGA11, ITGB4 and ITGB8 in human non-small cell lung cancer
}

\author{
PanCheng Wu ${ }^{\text {Equal first author, } 1}{ }^{1}$, Yanyu Wang ${ }^{\text {Equal first author, }{ }^{1}, \text { Yijun Wu }}{ }^{2}$, Ziqi Jia ${ }^{2}$, Yang Song ${ }^{3}$, Naixin Liang ${ }^{\text {Corresp. } 3}$ \\ ${ }^{1}$ Department of Thoracic Surgery, Peking Union Medical College Hospital,Peking Union Medical College, Chinese Academy of Medical Sciences, Beijing, \\ CHINA \\ 2 Peking Union Medical College, Eight-Year MD Program, Chinese Academy of Medical Sciences, Beijing, CHINA \\ 3 Department of Thoracic Surgery, Peking Union Medical College Hospital, Chinese Academy of Medical Sciences, Beijing, CHINA \\ Corresponding Author: Naixin Liang \\ Email address: pumchnelson@163.com
}

\section{Background}

Integrins play a crucial role in the regulation process of cell proliferation, migration, differentiation, tumor invasion and metastasis. ITGA11, ITGB4 and ITGB8 are three encoding genes of integrins family. Accumulative evidences have proved that abnormal expression of ITGA11, ITGB4 and ITGB8 are a common phenomenon in different malignances. However, their expression patterns and prognostic roles for patients with non-small cell lung cancer (NSCLC) have not been completely illustrated.

\section{Methods}

We investigated the expression patterns and prognostic values of ITGA11, ITGB4 and ITGB8 in patients with NSCLC through using a series of databases and various datasets, including ONCOMINE, GEPIA, HPA, TCGA and GEO datasets.

\section{Results}

We found that the expression levels of ITGAII and ITGB4 were significantly upregulated in both LUAD and LUSC, while ITGB8 was obviously upregulated in LUSC. Additionally, higher expression level of ITGB4 revealed a worse OS in LUAD.

\section{Conclusion}

Our findings suggested that ITGAII and ITGB4 might have the potential ability to act as diagnostic biomarkers for both LUAD and LUSC, while ITGB8 might serve as diagnostic biomarker for LUSC. Furthermore, ITGB4 could serve as a potential prognostic biomarker for LUAD. 


\section{Expression and prognostic analyses of $I T G A 11, I T G B 4$ and $I T G B 8$}

\section{2 in human non-small cell lung cancer}

3 Pancheng $\mathrm{Wu}^{1 *}$, Yanyu Wang ${ }^{1 *}$, Yijun $\mathrm{Wu}^{3}$, Ziqi $\mathrm{Jia}^{3}$, Yang Song ${ }^{2}$, Naixin Liang ${ }^{2 \dagger}$

$4{ }^{1}$ Department of Thoracic Surgery, Peking Union Medical College Hospital, Peking Union

5 Medical College, Chinese Academy of Medical Sciences, Beijing 100730, China

$6{ }^{2}$ Department of Thoracic Surgery, Peking Union Medical College Hospital, Chinese Academy of

7 Medical Sciences, Beijing, Beijing, China

8 3Peking Union Medical College, Eight-Year MD Program, Chinese Academy of Medical

9 Sciences, Beijing 100730, China

10 Corresponding Author:

11 Naixin Liang, MD. Department of Thoracic Surgery, Peking Union Medical College Hospital,

12 Chinese Academy of Medical Sciences, Beijing 100730, China. Email address:

13 pumchnelson@163.com.

\section{Abstract \\ Background}

Integrins play a crucial role in the regulation process of cell proliferation, migration, differentiation, tumor invasion and metastasis. ITGA11, ITGB4 and ITGB 8 are three encoding genes of integrins family. Accumulative evidences have proved that abnormal expression of $I T G A 11, I T G B 4$ and $I T G B 8$ are a common phenomenon in different malignances. However, their expression patterns and prognostic roles for patients with non-small cell lung cancer (NSCLC) have not been completely illustrated.

\section{Methods}

We investigated the expression patterns and prognostic values of ITGA11, ITGB4 and $I T G B 8$ in patients with NSCLC through using a series of databases and various datasets, including ONCOMINE, GEPIA, HPA, TCGA and GEO datasets.

\section{Results}

We found that the expression levels of ITGA11 and ITGB4 were significantly upregulated in both LUAD and LUSC, while ITGB 8 was obviously upregulated in LUSC. Additionally, higher expression level of ITGB4 revealed a worse OS in LUAD. 


\section{Conclusion}

Our findings suggested that ITGA11 and ITGB4 might have the potential ability to act as diagnostic biomarkers for both LUAD and LUSC, while ITGB8 might serve as diagnostic biomarker for LUSC. Furthermore, ITGB4 could serve as a potential prognostic biomarker for LUAD.

\section{Introduction}

Lung cancer is the most frequent malignancy and the leading cause of cancer-related death all over the world. Five-year survival rate for lung cancer patients ranges from $4 \%$ to $17 \%$ depending on disease stage and regional differences (Hirsch et al. 2017). Non-small cell lung cancer (NSCLC) is the most common pathological type of lung cancer and responsible for 85\% to $90 \%$ of all lung cancer (Osmani et al. 2018). Owing to the problems in early diagnosis, patients with NSCLC are often diagnosed at advanced stage, which contributes a lot to the dismal prognosis (Ellis \& Vandermeer 2011; Jan et al. 2019). Thus, there is an urgent need to discover new diagnostic and prognostic biomarkers for NSCLC.

Integrins function as bridges between the extracellular matrix (ECM) and the cytoskeleton and work as radars to detect changes in the cellular microenvironment, which enables cells to react according the external milieu (Bianconi et al. 2016; Ginsberg 2014). They play a crucial role in the regulation process of cell proliferation, migration, differentiation, tumor invasion and metastasis (Slack-Davis \& Parsons 2004). Integrins family include 24 different transmembrane, multifunctional heterodimers and are composed of an $\alpha$ and a $\beta$ subunit (Brakebusch et al. 2002). There are 18 different $\alpha$ subunits and 8 different $\beta$ subunits in human body (Hynes 1992). Recently, the effects of integrins in tumor progression have been receiving a great deal of attention. ITGA11 encodes integrin subunit $\alpha 11$, which dimerizes with $\beta 1$ subunit and forms as a cell surface collagen receptor involved in the process of cell migration and collagen reorganization (Tiger et al. 2001). Integrin $\alpha 11$ was overexpressed in the stroma of most head and neck squamous cell carcinomas (HNSCC) and correlated positively with alpha smooth muscle actin expression (Parajuli et al. 2017). In addition, ITGA11 was overexpressed by cancer-associated fibroblast (CAFs) in Pancreatic Ductal Adenocarcinoma (PDAC) stroma and may serve as an interesting stromal therapeutic target (Schnittert et al. 2019). Integrin subunit $\beta 4$, also known as a laminin-5 receptor, is a protein encoded by ITGB4 (Wang et al. 2012). Inhibition of ITGB4 in glioma cells would decrease the self-renewal abilities of glioma stem cells and suppress the 
62 malignant behaviors of glioma cells in vitro and in vivo (Ma et al. 2019). Moreover, higher

63 ITGB4 expression level was detected in tumor than adjacent non-tumor tissues in patients with

64 hepatocellular carcinoma (HCC). Silencing of ITGB4 could repress cell proliferation, colony

65 forming ability and cell invasiveness ( $\mathrm{Li}$ et al. 2017). Integrin $\beta 8$, paired with $\alpha \mathrm{v}$ subunit, is

66 encoded by $I T G B 8$. It has been reported that $I T G B 8$ is upregulated in laryngeal squamous cell

67 carcinoma ( $\mathrm{Ni}$ et al. 2012). Additionally, The expression level of $I T G B 8$ can be regulated by the

68 tumor-promoting receptor tyrosine kinase-EphB4, while knockdown of ITGB8 may suppress

69 migration and invasion in prostate cancer cell lines (Mertens-Walker et al. 2015). These studies

70 have shown that ITGAII, ITGB4 and ITGB8 might be candidate biomarkers and therapeutic

71 targets with great potential.

72 Recent years, there have been developed multifarious platforms, databases as well as

73 various datasets on the web that allow cancer researchers to make in-depth bioinformatic

74

75

76

77

78

79

80

81

82

83

84

85

86

87

88

89

90

91

analysis in cancer with multi omics data. Several prognostic biomarkers with great potential for

NSCLC have also been identified. For instance, It has been reported that STMN1 expression was correlated with poor OS in patients with Squamous Cell Lung Carcinoma (LUSC) and might serve as a prognostic biomarker (Bao et al. 2017). Using bioinformatics methods, Xie et al. have found that KRT8 expression might be an independent prognostic biomarker for poor OS and PFS in Lung Adenocarcinoma (LUAD) (Xie et al. 2019). Sun et al. have identified five genes that could predict metastasis in NSCLC and might serve as potential targets (Sun et al. 2019). As far as we know, bioinformatics analysis has not been applied to explore the roles of ITGA11, ITGB4 and ITGB 8 in NSCLC. Therefore, we conducted this study to analyze the expression patterns and prognostic values of these three genes in NSCLC based on online databases, platforms and various datasets.

\section{Materials and Methods}

\section{ONCOMINE analysis}

The expression levels of ITGAI1, ITGB4 and ITGB8 and genes co-expressed with ITGAI1, ITGB4 and ITGB8 were analyzed in ONCOMINE database (https://www.oncomine.org) (Rhodes et al. 2007; Rhodes et al. 2004). The cut-off of $p$ value and fold change were defined as 0.01 and 2, respectively (Huang et al. 2019).

\section{GEPIA (Gene Expression Profiling Interactive Analysis) analysis}


92 GEPIA (http:/gepia.cancer-pku.cn/) is an interactive web application for gene expression 93 analysis based on 9736 tumors and 8587 normal samples from the TCGA (The Cancer Genome 94 Atlas) and the GTEx (Genotype-Tissue Expression) databases (Tang et al. 2017). The GEPIA 95 database was used to compare mRNA levels of ITGA11, ITGB4 and ITGB8 between TCGA and 96 GTEx databases. Meanwhile, the association among ITGA11, ITGB4 and ITGB8 in NSCLC were 97 also analyzed in GEPIA.

98

\section{Bioinformatics analysis of data using The Cancer Genome Atlas lung cancer datasets} The level 3 data of TCGA-LUAD and TCGA-LUSC were obtained from UCSC Xena platform (https://xenabrowser.net/datapages/) (Goldman et al. 2015) and RTCGA package (https://rtcga.github.io/RTCGA). The LUAD and LUSC gene expression RNAseq datasets included 524 tumor tissues and 499 tumor tissues, respectively. 502 of the LUAD patients and 492 of the 499 LUSC patients had complete survival data. The differences in overall survival (OS) of LUAD and LUSC patients with high and low expression of ITGA11, ITGB4 and ITGB8 were assessed by Kaplan-Meier curves. Meanwhile, the association between tumor stage and the expression levels of ITGA11, ITGB4 and ITGB 8 were also analyzed. Clinicopathological parameters, including age at diagnosis, gender, vital status, tumor stage, smoking history and OS time, were extracted for univariate and multivariate cox regression analysis.

\section{Gene Expression Omnibus (GEO) microarray datasets analysis}

To validate the expression profiles of ITGA11, ITGB4 and ITGB8 in NSCLC, we collected a total of 21 datasets including tumor and non-tumor tissues of NSCLC in GEO database (https://www.ncbi.nlm.nih.gov/geo/). We analyzed the mRNA levels of ITGA11, ITGB4 and ITGB 8 between tumor and non-tumor controls for each GEO dataset. In addition, we performed a meta-analysis based on the enrolled GEO microarray datasets.

\section{Immunohistochemistry analysis}

The protein expression of ITGA11, ITGB4 and ITGB8 in normal lung and tumor tissues were examined using the Human Protein Atlas (HPA) (https://www.proteinatlas.org/) (Uhlen et al. 2015; Uhlen et al. 2017).

\section{Statistical analysis}

Statistical analysis was performed on R software (3.6.1) (https://www.r-project.org/) and an integrated development environment RStudio (1.2.1335) (https://rstudio.com/). The mRNA expression of ITGA11, ITGB 4 and ITGB8 between NSCLC tissues and normal controls were 
123 compared using Student's t-test. Data visualization was performed using an R package called

124

125

126

127

128

129

130

131

132

133

134

135

136

137

138

139

140

141

142

143

144

145

146

147

148

149

150

151

152

153

"ggstatsplot" (https://CRAN.R-project.org/package=ggstatsplot). Kaplan-Meier curves of OS were performed in TCGA-LUAD and TCGA-LUSC raw data by setting median expression of ITGA11, ITGB4 and ITGB8 as cut-off. Statistical differences were assessed by the log-rank test. Univariate and multivariate survival analyses were performed using cox regression model, risk factors $(p<0.2)$ analyzed by univariate analysis were selected for multivariate analysis.

For GEO datasets analysis, mean (M) and standard deviation (SD) were calculated for each NSCLC tumor and normal control group. In addition, an R package called "meta" was used in R to perform a comprehensive meta-analysis (Schwarzer 2007). The Q test and $I^{2}$ statistic were calculated to assess the heterogeneity among the enrolled studies. If $p<0.05$ or $l^{2}>50 \%$, a random effects model would be selected. Sensitivity analysis was conducted to explore whether a specific study played a crucial influence in significant heterogeneity. Finally, the publication bias was examined through funnel plots and Egger's test (Egger et al. 1997). Once there was a publication bias, the "fill and trim" method would be selected to adjust for the bias (Duval \& Tweedie 2000). $p<0.05$ deemed statistically significant.

\section{Results}

The expression levels of ITGA11, ITGB4 and ITGB 8 in patients with non-small cell lung cancer.

Using ONCOMINE database, we investigated the transcription levels of ITGA11, ITGB4 and $I T G B 8$ in lung cancer vs. normal samples. ONCOMINE analysis revealed that the mRNA expression of ITGA11, ITGB4 and ITGB8 were obviously overexpressed in NSCLC tissues in ten datasets (Figure 1). These datasets were summarized in Table 1. The GEPIA analysis results also suggested that the expression levels of ITGAII and ITGB4 were significantly higher in both LUAD and LUSC than that in normal tissues, while the expression level of ITGB 8 was only significantly upregulated in LUSC tissues (Figure 2). Furthermore, we analyzed ITGA11, ITGB4 and ITGB 8 mRNA expression level in both lung cancer and normal tissues using the TCGALUAD and TCGA-LUSC original data. The results revealed that the expression levels of ITGA11, ITGB4 and ITGB8 were all significantly upregulated in tumor tissues compared with normal tissues (Figure S1).

To further explore the protein expression of ITGA11, ITGB4 and ITGB8 in NSCLC, we analyzed the IHC images using the Human Protein Atlas (HPA) database. As shown in Figure 3, 
154 the protein expression of ITGAI1 and ITGB4 were upregulated in both LUAD and LUSC cancer 155 tissues compared with normal lung tissues (Figure 3A-C and Figure 3D-F). In comparison, the 156 protein expression of ITGB8 was obviously upregulated in LUSC with medium staining, but not 157 in LUAD (Figure 3G-I).

158 Confirmation of the expression profiles of ITGA11, ITGB4 and ITGB8 in non-small cell 159 lung cancer using GEO datasets.

160 We also performed a data-mining analysis to investigate the differences in the expression 161 levels of ITGA11, ITGB4 and ITGB8 between tumor and normal tissues in NSCLC using GEO 162 datasets. The main characteristics of the enrolled GEO studies were described in Table S1. The

163

164 165

166

167

168

169

170

171

172

173

174

175

176

177

178

179

180

181

182

183

results were shown in Figure 4 and Figure S2-S4. As illustrated in Figure 4A and Figure S2D, the expression level of ITGB4 was significantly increased in tissues from patients with LUAD (SMD: 0.94; 95\%CI: 0.65-1.24; $p<0.01$ ) as well as LUSC (SMD:1.37; 95\% CI: 0.71-2.04; $p<$ $0.01)$ compared to the normal tissues. The heterogeneity was apparent for $\operatorname{LUAD}\left(I^{2}=80 \% ; p<\right.$ $0.01)$ and LUSC $\left(I^{2}=89 \% ; p<0.01\right)$. The following sensitivity analysis demonstrated that no study was found to have a vital influence in the enrolled studies (Figure 4B and Figure S3D). In addition, we didn't find evidence of publication bias based on the funnel plot and the Egger's test (Figure 4C, $p=0.7759$ ). However, the Figure S4D indicated publication bias (Egger's test, $p=$ 0.04729). Therefore, we used the fill and trim method to adjust for the bias. The adjusted random effects model result showed that ITGB4 was also significantly upregulated in LUSC tissues (SMD: 0.77; 95\%CI: 0.03-1.52; $p=0.04$ ).

The analysis results of ITGA11 and ITGB8 mRNA levels in LUAD and LUSC were the same as the above results (Figure S2-S4). The separate analyses of the expression levels of ITGA 1 1, ITGB4 and ITGB8 in LUAD and LUSC tissues compared with normal tissues for each GEO dataset were presented in the Figure S5 and Figure S6.

\section{The prognostic values of ITGA11, ITGB4 and ITGB8 in non-small cell lung cancer.}

By using GEPIA, we investigated the prognostic values of ITGA11, ITGB4 and ITGB 8 in NSCLC. The survival curves revealed that high expression level of ITGB4 could indicate a poor OS in LUAD $(p<0.001$; Figure 5B), while ITGAI1 and ITGB 8 were not related with OS in LUAD ( $p=0.064$ and $p=0.78$, respectively, Figure 5A and 5C). In comparison, there were no obvious associations between the expression levels of ITAG11, ITGB4 and ITGB8 and LUSC 
184 (Figure 5D-5F). Moreover, using the TCGA original data, we performed survival analysis to 185 validate these associations. The results were consistent with GEPIA analysis (Figure S7).

186 Next, we performed cox regression analysis to further assess and validate the prognostic 187 values of ITGA1 1, ITGB4 and ITGB8 in NSCLC based on TCGA original data. The univariate 188 cox analysis indicated that high $I T G B 4$ expression and advanced stages were significantly 189 correlated with worse OS in LUAD (Table 2). Meanwhile, multivariate cox analysis confirmed 190 that high ITGB4 expression was an independent prognostic biomarker for patients with LUAD 191 (HR: 1.417; 95\%CI: 1.042-1.926; $p=0.026$; Table 2). In addition, no significant results were 192 found with other genes in the OS of LUAD and LUSC (Table 2). These results were consistent 193 with that analyzed by GEPIA. Furthermore, we investigated the correlation between tumor stage 194 and the expression levels of ITGAI1, ITGB4 and ITGB8 (Figure S8). The results showed that 195 there was a significant correlation between tumor stage and mRNA expression of ITGB8 in 196 LUSC (Figure S8F).

197 Co-expression and correlation analyses of ITGA11, ITGB4 and ITGB8 in non-small cell 198 lung cancer.

199

200

The co-expression analysis was conducted using ONCOMINE database. Based on Hou Lung dataset (Hou et al. 2010), we analyzed genes that were co-expressed with ITGA11, the 201 result showed that ITGA11 was co-expressed with COL10A1, THBS2, SULF1, CTRHC1, 202 GREM1, C5orf46, COL11A1, NOX4 (Figure S9A). The Bild Lung dataset indicated that ITGB4 203 was co-expressed with LAD1, SFN, FXYD3, KRT19, DSG2, JUP, DSP, PERP (Bild et al. 2006)

204

205

206

207

208

209

210

211

212 213

214 (Figure S9B). Based on Yamagata Lung dataset (Yamagata et al. 2003), we analyzed genes that were co-expressed with $I T G B 8$, the result showed that $I T G B 8$ was co-expressed with ERC2, PDE6D, C17orf99, SNRNP27, C1 orf61, GATA1, PPP2R2B, CCK, CRYBA1, APBA3, CYP3A4, UROS (Figure S9C).

By using GEPIA, we investigated the association among ITGA11, ITGB4 and ITGB8 in NSCLC based on Pearson correlation analysis. The results indicated that there was no correlation between ITGAII and ITGB4 $(\mathrm{R}=-0.018 ; p>0.05)$ (Figure S10A). Also, there was scarcely any correlation between $I T G A 11$ and $I T G B 8(\mathrm{R}=0.069 ; p<0.05)$ (Figure $\mathrm{S} 10 \mathrm{~B})$. In addition, a weak positive correlation was found between $I T G B 8$ and $I T G B 4(\mathrm{R}=0.32 ; p<0.05)$ (Figure $\mathrm{S} 10 \mathrm{C}$ ).

\section{Discussion}

Numerous studies have suggested that ITGA11, ITGB4 and ITGB8 are involved in 
215 migration, epithelial-mesenchymal transition, invasion, and metastasis in different cancers (Gan 216 et al. 2018; Huang et al. 2017; Kitajiri et al. 2002; Li et al. 2017). The aberrant expression of 217 ITGA11, ITGB4, and ITGB8 have been reported in many cancers (Grossman et al. 2000; 218 Mertens-Walker et al. 2015; Parajuli et al. 2017; Tagliabue et al. 1998). Regrettably, the 219 expression profiles and prognostic roles of ITGA11, ITGB4 and ITGB8 in NSCLC are still not 220 clear. Thus, we conducted this study to explore the expression patterns and prognostic values of 221 ITGA11, ITGB4 and ITGB8 in NSCLC.

222 It has been reported that ITGA11 could serve as an important stromal factor in NSCLC, 223 which can enhance tumorigenicity of human non-small cell lung cancer cells by regulating IGF2 224 expression in fibroblasts (Zhu et al. 2007). Moreover, in carcinoma-associated fibroblasts 225 (CAFs), ITGA11 signaling pathway may play an important role in carcinoma-associated 226 fibroblasts (CAFs), which means Integrin $\alpha 11 \beta 1$ can promote tumor growth and metastatic 227 potential of NSCLC cells by regulating cancer stromal stiffness (Navab et al. 2016). These 228 results suggested that ITGA11 might play an important role for NSCLC. In our study, 229 ONCOMINE analysis showed that mRNA expression level of ITGA11 was highly expressed in Lung Adenocarcinoma compared with that in normal controls. GEPIA revealed that the expression level of ITGA11 was obviously higher in both LUAD and LUSC than that in normal tissues. In addition, we also downloaded TCGA original data, GEO datasets, and protein data from HPA to validate ITGA11 expression profile, the results were consistent with the GEPIA analysis results. These results indicated that ITGA11 might be a diagnostic biomarker for patients with LUAD and LUSC. Furthermore, we investigated the association between the expression level of ITGA11 and OS in LUAD and LUSC using GEPIA and cox regression analysis. However, the results showed ITGA11 expression had no prognostic role in terms of OS in LUAD and LUSC.

$I T G B 4$ was found to have a strong positive correlation with tumor size $(p=0.01)$ and tumor nuclear grade $(p<0.01)$ in early breast cancer (Diaz et al. 2005). Furthermore, it is reported that ITGB4 could promote the invasion and metastasis of tumor cells through a 242 series of processes (Stewart \& O'Connor 2015). These results imply us that ITGB4 might also 243 play a crucial role in NSCLC. In our report, ONCOMINE and GEPIA analysis revealed that the 244 expression level of ITGB4 was significantly upregulated in LUAD and LUSC. Additionally, we 245 confirmed this expression feature by analysis TCGA original data and GEO datasets. The protein 
246 level was also consistent with the mRNA expression level. Taken together, these results implied 247 that ITGB4 expression could act as a diagnostic biomarker for patients with LUAD and LUSC.

248 Moreover, the survival curve showed that high ITGB4 expression was strong correlated with 249 inferior OS in LUAD. The following univariate cox and multivariate cox regression analysis 250 confirmed that high ITGB4 expression level was an independent prognostic biomarker for poor 251 OS in LUAD.

252 It has been reported that ITGB8 could mediate the activation of latent TGF- $\beta$, which 253 subsequently derives the epithelial-to-mesenchymal (EMT) transition of some cancers and 254 contributes to cancer cell migration and growth (Mu et al. 2002; Pozzi \& Zent 2011).

255 Furthermore, ITGB8 was significantly upregulated in ovarian cancer tissues compared with that 256 in normal ovary tissues (He et al. 2018). Moreover, It has been reported that ITGB8 silencing 257 could suppress the metastatic potential of human lung cancer cell lines A549 and PC (Xu \& Wu 258 2012). These studies suggested that ITGB8 might play an important role in NSCLC. In our study, 259 we found that the mRNA expression level of ITGB8 was highly overexpressed in LUSC both in

260

261

262

263

264

265

266

267

268

269

270

271

272

273

274

275 276 ONCOMINE and GEPIA analysis. This expression feature was successfully validated by analyzing the TCGA original data and GEO datasets. These results suggested that ITGB 8 might act as a diagnostic biomarker in LUSC. It was worth mentioning that there was no significant correlation in ITGB 8 expression level between LUAD and normal tissues by GEPIA analysis. However, the expression feature was not showed when we analyzed the TCGA original data and GEO datasets. This may due to the lack of normal controls in TCGA datasets and the differences in enrolled participants in GEO datasets. Future large-scale studies are required to assess and validate this expression pattern. In addition, we explored the association between the expression level of ITGB 8 and OS in LUAD and LUSC using GEPIA and cox regression analysis. the results showed ITGB8 expression had no prognostic role in terms of OS in LUAD and LUSC. Furthermore, we found that there was a strong correlation between ITGB8 expression level and tumor stage in LUSC.

The potential limitations of our study need to be noted. First, the biological mechanisms of these three candidate markers in LUAD and LUSC are still unknown. Second, although this study had a comprehensive analysis based on several databases such as TCGA and GEO, traditional in-house experimental studies including enough specimens are required to further validate our findings. 


\section{Conclusions}

278 In summary, we systematically analyzed the expression patterns and prognostic values of

$279 I T G A 11, I T G B 4$ and ITGB8 in patients with LUAD and LUSC by conducting a bioinformatics

280 analysis based on several web platforms and various datasets. Our results indicated that ITGA11

281 and ITGB4 might act as diagnostic biomarkers for both LUAD and LUSC, while ITGB 8 may

282 serve as diagnostic biomarker for LUSC. Furthermore, ITGB4 might serve as a potential

283 prognostic biomarker for LUAD. We hope our findings will enrich the knowledge of diagnostic

284 and therapy designs for patients with NSCLC.

\section{Acknowledgements}

286 We'd like to thank Dr. Yi Zheng for her kind encouragement during the study period.

287

288

289

290

291

292

293

294

295

296

297

298

299

300

301

302

303

304

305

306

307

308

309

310

311

312

313

314

315

316

317

\section{References:}

Bao P, Yokobori T, Altan B, lijima M, Azuma Y, Onozato R, Yajima T, Watanabe A, Mogi A, Shimizu K, Nagashima T, Ohtaki Y, Obayashi K, Nakazawa S, Bai T, Kawabata-Iwakawa R, Asao T, Kaira K, Nishiyama M, and Kuwano H. 2017. High STMN1 Expression is Associated with Cancer Progression and Chemo-Resistance in Lung Squamous Cell Carcinoma. Ann Surg Oncol 24:4017-4024. 10.1245/s10434-017-6083-0

Bianconi D, Unseld M, and Prager GW. 2016. Integrins in the Spotlight of Cancer. Int J Mol Sci 17. 10.3390/ijms17122037

Bild AH, Yao G, Chang JT, Wang Q, Potti A, Chasse D, Joshi MB, Harpole D, Lancaster JM, Berchuck A, Olson JA, Jr., Marks JR, Dressman HK, West M, and Nevins JR. 2006. Oncogenic pathway signatures in human cancers as a guide to targeted therapies. Nature 439:353-357. 10.1038/nature04296

Brakebusch C, Bouvard D, Stanchi F, Sakai T, and Fassler R. 2002. Integrins in invasive growth. J Clin Invest 109:999-1006. 10.1172/JCl15468

Diaz LK, Cristofanilli M, Zhou X, Welch KL, Smith TL, Yang Y, Sneige N, Sahin AA, and Gilcrease MZ. 2005. Beta4 integrin subunit gene expression correlates with tumor size and nuclear grade in early breast cancer. Mod Pathol 18:1165-1175. 10.1038/modpathol.3800411

Duval S, and Tweedie R. 2000. Trim and fill: A simple funnel-plot-based method of testing and adjusting for publication bias in meta-analysis. Biometrics 56:455-463.

Egger M, Davey Smith G, Schneider M, and Minder C. 1997. Bias in meta-analysis detected by a simple, graphical test. BMJ 315:629-634. 10.1136/bmj.315.7109.629

Ellis PM, and Vandermeer R. 2011. Delays in the diagnosis of lung cancer. J Thorac Dis 3:183188. 10.3978/j.issn.2072-1439.2011.01.01

Gan L, Meng J, Xu M, Liu M, Qi Y, Tan C, Wang Y, Zhang P, Weng W, Sheng W, Huang M, and Wang Z. 2018. Extracellular matrix protein 1 promotes cell metastasis and glucose metabolism by inducing integrin beta4/FAK/SOX2/HIF-1alpha signaling pathway in gastric cancer. Oncogene 37:744-755. 10.1038/onc.2017.363 
318

319

320

321

322

323

324

325

326

327

328

329

330

331

332

333

334

335

336

337

338

339

340

341

342

343

344

345

346

347

348

349

350

351

352

353

354

355

356

357

358

359

360

361

362

363

364

365

366

367

368

Ginsberg MH. 2014. Integrin activation. BMB Rep 47:655-659.

Goldman M, Craft B, Swatloski T, Cline M, Morozova O, Diekhans M, Haussler D, and Zhu J. 2015. The UCSC Cancer Genomics Browser: update 2015. Nucleic Acids Res 43:D812817. 10.1093/nar/gku1073

Grossman HB, Lee C, Bromberg J, and Liebert M. 2000. Expression of the alpha6beta4 integrin provides prognostic information in bladder cancer. Oncol Rep 7:13-16.

He J, Liu Y, Zhang L, and Zhang H. 2018. Integrin Subunit beta 8 (ITGB8) Upregulation Is an Independent Predictor of Unfavorable Survival of High-Grade Serous Ovarian Carcinoma Patients. Med Sci Monit 24:8933-8940. 10.12659/MSM.911518

Hirsch FR, Scagliotti GV, Mulshine JL, Kwon R, Curran WJ, Jr., Wu YL, and Paz-Ares L. 2017. Lung cancer: current therapies and new targeted treatments. Lancet 389:299-311. 10.1016/S0140-6736(16)30958-8

Hou J, Aerts J, den Hamer B, van ljcken W, den Bakker M, Riegman P, van der Leest C, van der Spek P, Foekens JA, Hoogsteden HC, Grosveld F, and Philipsen S. 2010. Gene expression-based classification of non-small cell lung carcinomas and survival prediction. PLoS One 5:e10312. 10.1371/journal.pone.0010312

Huang C, Liu J, Xiong B, Yonemura Y, and Yang X. 2019. Expression and prognosis analyses of forkhead box A (FOXA) family in human lung cancer. Gene 685:202-210. 10.1016/j.gene.2018.11.022

Huang L, Cai JL, Huang PZ, Kang L, Huang MJ, Wang L, and Wang JP. 2017. miR19b-3p promotes the growth and metastasis of colorectal cancer via directly targeting ITGB8. Am $J$ Cancer Res 7:1996-2008.

Hynes RO. 1992. Integrins: versatility, modulation, and signaling in cell adhesion. Cell 69:11-25.

Jan YH, Lai TC, Yang CJ, Huang MS, and Hsiao M. 2019. A co-expressed gene status of adenylate kinase $1 / 4$ reveals prognostic gene signature associated with prognosis and sensitivity to EGFR targeted therapy in lung adenocarcinoma. Sci Rep 9:12329. 10.1038/s41598-019-48243-9

Kitajiri S, Hosaka N, Hiraumi H, Hirose T, and Ikehara S. 2002. Increased expression of integrin beta-4 in papillary thyroid carcinoma with gross lymph node metastasis. Pathol Int 52:438441.

Li XL, Liu L, Li DD, He YP, Guo LH, Sun LP, Liu LN, Xu HX, and Zhang XP. 2017. Integrin beta4 promotes cell invasion and epithelial-mesenchymal transition through the modulation of Slug expression in hepatocellular carcinoma. Sci Rep 7:40464. 10.1038/srep40464

Ma B, Zhang L, Zou Y, He R, Wu Q, Han C, and Zhang B. 2019. Reciprocal regulation of integrin beta4 and KLF4 promotes gliomagenesis through maintaining cancer stem cell traits. $J$ Exp Clin Cancer Res 38:23. 10.1186/s13046-019-1034-1

Mertens-Walker I, Fernandini BC, Maharaj MS, Rockstroh A, Nelson CC, Herington AC, and Stephenson SA. 2015. The tumour-promoting receptor tyrosine kinase, EphB4, regulates expression of integrin-beta8 in prostate cancer cells. BMC Cancer 15:164. 10.1186/s12885-015-1164-6

Mu D, Cambier S, Fjellbirkeland L, Baron JL, Munger JS, Kawakatsu H, Sheppard D, Broaddus VC, and Nishimura SL. 2002. The integrin alpha(v)beta8 mediates epithelial homeostasis through MT1-MMP-dependent activation of TGF-beta1. J Cell Biol 157:493-507. 10.1083/jcb.200109100

Navab R, Strumpf D, To C, Pasko E, Kim KS, Park CJ, Hai J, Liu J, Jonkman J, Barczyk M, Bandarchi B, Wang YH, Venkat K, Ibrahimov E, Pham NA, Ng C, Radulovich N, Zhu CQ, Pintilie M, Wang D, Lu A, Jurisica I, Walker GC, Gullberg D, and Tsao MS. 2016. Integrin alpha11beta1 regulates cancer stromal stiffness and promotes tumorigenicity and metastasis in non-small cell lung cancer. Oncogene 35:1899-1908. 10.1038/onc.2015.254

Ni RS, Shen X, Qian X, Yu C, Wu H, and Gao X. 2012. Detection of differentially expressed genes and association with clinicopathological features in laryngeal squamous cell carcinoma.

Peer) reviewing PDF | (2019:08:40400:2:0:NEW 10 Nov 2019) 
369

370

371

372

373

374

375

376

377

378

379

380

381

382

383

384

385

386

387

388

389

390

391

392

393

394

395

396

397

398

399

400

401

402

403

404

405

406

407

408

409

410

411

412

413

414

415

416

417

418

419

Oncol Lett 4:1354-1360. 10.3892/ol.2012.920

Osmani L, Askin F, Gabrielson E, and Li QK. 2018. Current WHO guidelines and the critical role of immunohistochemical markers in the subclassification of non-small cell lung carcinoma (NSCLC): Moving from targeted therapy to immunotherapy. Semin Cancer Biol 52:103109. 10.1016/j.semcancer.2017.11.019

Parajuli H, Teh MT, Abrahamsen S, Christoffersen I, Neppelberg E, Lybak S, Osman T, Johannessen AC, Gullberg D, Skarstein K, and Costea DE. 2017. Integrin alpha11 is overexpressed by tumour stroma of head and neck squamous cell carcinoma and correlates positively with alpha smooth muscle actin expression. J Oral Pathol Med 46:267-275. 10.1111/jop.12493

Pozzi A, and Zent R. 2011. TGF-beta sequestration by mesangial cell integrin alphavbeta8: A novel mechanism of glomerular endothelial cell regulation. Am J Pathol 178:485-489. 10.1016/j.ajpath.2010.10.038

Rhodes DR, Kalyana-Sundaram S, Mahavisno V, Varambally R, Yu J, Briggs BB, Barrette TR, Anstet MJ, Kincead-Beal C, Kulkarni P, Varambally S, Ghosh D, and Chinnaiyan AM. 2007. Oncomine 3.0: genes, pathways, and networks in a collection of 18,000 cancer gene expression profiles. Neoplasia 9:166-180.

Rhodes DR, Yu J, Shanker K, Deshpande N, Varambally R, Ghosh D, Barrette T, Pandey A, and Chinnaiyan AM. 2004. ONCOMINE: a cancer microarray database and integrated datamining platform. Neoplasia 6:1-6.

Schnittert J, Bansal R, Mardhian DF, van Baarlen J, Ostman A, and Prakash J. 2019. Integrin alpha11 in pancreatic stellate cells regulates tumor stroma interaction in pancreatic cancer. FASEB J:fj201802336R. 10.1096/fj.201802336R

Schwarzer G. 2007. meta: An R Package for Meta-Analysis. R News 7:40-45.

Slack-Davis JK, and Parsons JT. 2004. Emerging views of integrin signaling: implications for prostate cancer. J Cell Biochem 91:41-46. 10.1002/jcb.10665

Stewart RL, and O'Connor KL. 2015. Clinical significance of the integrin alpha6beta4 in human malignancies. Lab Invest 95:976-986. 10.1038/labinvest.2015.82

Sun R, Meng X, Wang W, Liu B, Lv X, Yuan J, Zeng L, Chen Y, Yuan B, and Yang S. 2019. Five genes may predict metastasis in non-small cell lung cancer using bioinformatics analysis. Oncol Lett 18:1723-1732. 10.3892/ol.2019.10498

Tagliabue E, Ghirelli C, Squicciarini P, Aiello P, Colnaghi MI, and Menard S. 1998. Prognostic value of alpha 6 beta 4 integrin expression in breast carcinomas is affected by laminin production from tumor cells. Clin Cancer Res 4:407-410.

Tang Z, Li C, Kang B, Gao G, Li C, and Zhang Z. 2017. GEPIA: a web server for cancer and normal gene expression profiling and interactive analyses. Nucleic Acids Res 45:W98W102. 10.1093/nar/gkx247

Tiger CF, Fougerousse F, Grundstrom G, Velling T, and Gullberg D. 2001. alpha11beta1 integrin is a receptor for interstitial collagens involved in cell migration and collagen reorganization on mesenchymal nonmuscle cells. Dev Biol 237:116-129. 10.1006/dbio.2001.0363

Uhlen M, Fagerberg L, Hallstrom BM, Lindskog C, Oksvold P, Mardinoglu A, Sivertsson A, Kampf C, Sjostedt E, Asplund A, Olsson I, Edlund K, Lundberg E, Navani S, Szigyarto CA, Odeberg J, Djureinovic D, Takanen JO, Hober S, Alm T, Edqvist PH, Berling H, Tegel H, Mulder J, Rockberg J, Nilsson P, Schwenk JM, Hamsten M, von Feilitzen K, Forsberg M, Persson L, Johansson F, Zwahlen M, von Heijne G, Nielsen J, and Ponten F. 2015. Proteomics. Tissue-based map of the human proteome. Science 347:1260419. 10.1126/science.1260419

Uhlen M, Zhang C, Lee S, Sjostedt E, Fagerberg L, Bidkhori G, Benfeitas R, Arif M, Liu Z, Edfors F, Sanli K, von Feilitzen K, Oksvold P, Lundberg E, Hober S, Nilsson P, Mattsson J, Schwenk JM, Brunnstrom H, Glimelius B, Sjoblom T, Edqvist PH, Djureinovic D, Micke P, Lindskog C, Mardinoglu A, and Ponten F. 2017. A pathology atlas of the human cancer

Peer) reviewing PDF | (2019:08:40400:2:0:NEW 10 Nov 2019) 
420

421

422

423

424

425

426

427

428

429

430

431

432

433

434

435

436

437 transcriptome. Science 357. 10.1126/science.aan2507

Wang L, Dong Z, Zhang Y, and Miao J. 2012. The roles of integrin beta4 in vascular endothelial cells. J Cell Physiol 227:474-478. 10.1002/jcp.22769

Xie L, Dang Y, Guo J, Sun X, Xie T, Zhang L, Yan Z, Amin H, and Guo X. 2019. High KRT8 Expression Independently Predicts Poor Prognosis for Lung Adenocarcinoma Patients. Genes (Basel) 10. 10.3390/genes10010036

Xu Z, and Wu R. 2012. Alteration in metastasis potential and gene expression in human lung cancer cell lines by ITGB8 silencing. Anat Rec (Hoboken) 295:1446-1454. 10.1002/ar.22521

Yamagata N, Shyr Y, Yanagisawa K, Edgerton M, Dang TP, Gonzalez A, Nadaf S, Larsen P, Roberts JR, Nesbitt JC, Jensen R, Levy S, Moore JH, Minna JD, and Carbone DP. 2003. A training-testing approach to the molecular classification of resected non-small cell lung cancer. Clin Cancer Res 9:4695-4704.

Zhu CQ, Popova SN, Brown ER, Barsyte-Lovejoy D, Navab R, Shih W, Li M, Lu M, Jurisica I, Penn LZ, Gullberg D, and Tsao MS. 2007. Integrin alpha 11 regulates IGF2 expression in fibroblasts to enhance tumorigenicity of human non-small-cell lung cancer cells. Proc Natl Acad Sci U S A 104:11754-11759. 10.1073/pnas.0703040104 


\section{Table $\mathbf{1}$ (on next page)}

The transcription levels of ITGA11, ITGB4 and ITGB8 between lung cancer and normal samples in ONCOMINE database. 


\begin{tabular}{|c|c|c|c|c|c|}
\hline Gene ID & Types of lung cancer vs. normal & Fold change & $P$ value & $\mathrm{t}$-Test & References \\
\hline \multirow{2}{*}{ ITGA11 } & Lung Adenocarcinoma vs. Normal & 2.047 & $6.79 \mathrm{E}-16$ & 10.685 & (Selamat et al. 2012) \\
\hline & Lung Adenocarcinoma vs. Normal & 2.968 & $7.47 \mathrm{E}-09$ & 7.945 & (Okayama et al. 2012) \\
\hline \multirow{6}{*}{ ITGB4 } & Squamous Cell Lung Carcinoma vs. Normal & 2.867 & $1.32 \mathrm{E}-05$ & 8.706 & (Wachi et al. 2005) \\
\hline & Squamous Cell Lung Carcinoma vs. Normal & 3.505 & $5.33 \mathrm{E}-06$ & 6.406 & (Garber et al. 2001) \\
\hline & Squamous Cell Lung Carcinoma vs. Normal & 2.637 & $4.64 \mathrm{E}-10$ & 7.458 & (Talbot et al. 2005) \\
\hline & Squamous Cell Lung Carcinoma vs. Normal & 6.818 & $5.21 \mathrm{E}-04$ & 3.57 & (Bhattacharjee et al. 2001) \\
\hline & Lung Adenocarcinoma vs. Normal & 2.99 & $1.17 \mathrm{E}-14$ & 9.575 & (Selamat et al. 2012) \\
\hline & Squamous Cell Lung Carcinoma vs. Normal & 3.591 & $8.92 \mathrm{E}-10$ & 8.599 & (Hou et al. 2010) \\
\hline \multirow{2}{*}{ ITGB8 } & Squamous Cell Lung Carcinoma vs. Normal & 2.455 & $1.95 \mathrm{E}-05$ & 5.627 & (Garber et al. 2001) $\square$ \\
\hline & Squamous Cell Lung Carcinoma vs. Normal & 2.876 & $1.26 \mathrm{E}-07$ & 6.484 & (Hou et al. 2010) $\square$ \\
\hline
\end{tabular}

1

2

\section{References:}

Bhattacharjee A, Richards WG, Staunton J, Li C, Monti S, Vasa P, Ladd C, Beheshti J, Bueno R, Gillette M, Loda M, Weber G, Mark EJ, Lander ES, Wong W, Johnson BE, Golub TR, Sugarbaker DJ, and Meyerson M. 2001. Classification of human lung carcinomas by mRNA expression profiling reveals distinct adenocarcinoma subclasses. Proc Natl Acad Sci U S A 98:13790-13795. 10.1073/pnas.191502998

Garber ME, Troyanskaya OG, Schluens K, Petersen S, Thaesler Z, Pacyna-Gengelbach M, van de Rijn M, Rosen GD, Perou CM, Whyte RI, Altman RB, Brown PO, Botstein D, and Petersen I. 2001. Diversity of gene expression in adenocarcinoma of the lung. Proc Natl Acad Sci U S A 98:13784-13789. 10.1073/pnas.241500798

Hou J, Aerts J, den Hamer B, van Ijcken W, den Bakker M, Riegman P, van der Leest C, van der Spek P, Foekens JA, Hoogsteden HC, Grosveld F, and Philipsen S. 2010. Gene expression-based classification of non-small cell lung carcinomas and survival prediction. PLoS One 5:e10312. 10.1371/journal.pone.0010312

Okayama H, Kohno T, Ishii Y, Shimada Y, Shiraishi K, Iwakawa R, Furuta K, Tsuta K, Shibata T, Yamamoto S, Watanabe S, Sakamoto H, Kumamoto K, Takenoshita S, Gotoh N, Mizuno H, Sarai A, Kawano S, Yamaguchi R, Miyano S, and Yokota J. 2012. Identification of genes upregulated in ALK-positive and EGFR/KRAS/ALK-negative lung adenocarcinomas. Cancer Res 72:100-111. 10.1158/0008-5472.CAN-111403

Selamat SA, Chung BS, Girard L, Zhang W, Zhang Y, Campan M, Siegmund KD, Koss MN, Hagen JA, Lam WL, Lam S, Gazdar AF, and Laird-Offringa IA. 2012. Genome-scale analysis of DNA methylation in lung adenocarcinoma and integration with mRNA expression. Genome Res 22:1197-1211. 10.1101/gr.132662.111

Talbot SG, Estilo C, Maghami E, Sarkaria IS, Pham DK, P Oc, Socci ND, Ngai I, Carlson D, Ghossein R, Viale A, Park BJ, Rusch VW, and Singh B. 2005. Gene expression profiling allows distinction between primary and metastatic squamous cell carcinomas in the lung. Cancer Res 65:3063-3071. 10.1158/0008-5472.CAN-041985

Wachi S, Yoneda K, and Wu R. 2005. Interactome-transcriptome analysis reveals the high centrality of genes differentially expressed in lung cancer tissues. Bioinformatics 21:4205-4208. 10.1093/bioinformatics/bti688 
Figure 1

The transcription levels of ITGA11, ITGB4 and ITGB8 in different cancers compared with normal tissues in the ONCOMINE dabase.

Cell color is determined by the best gene rank percentile for the analysis within the cell 


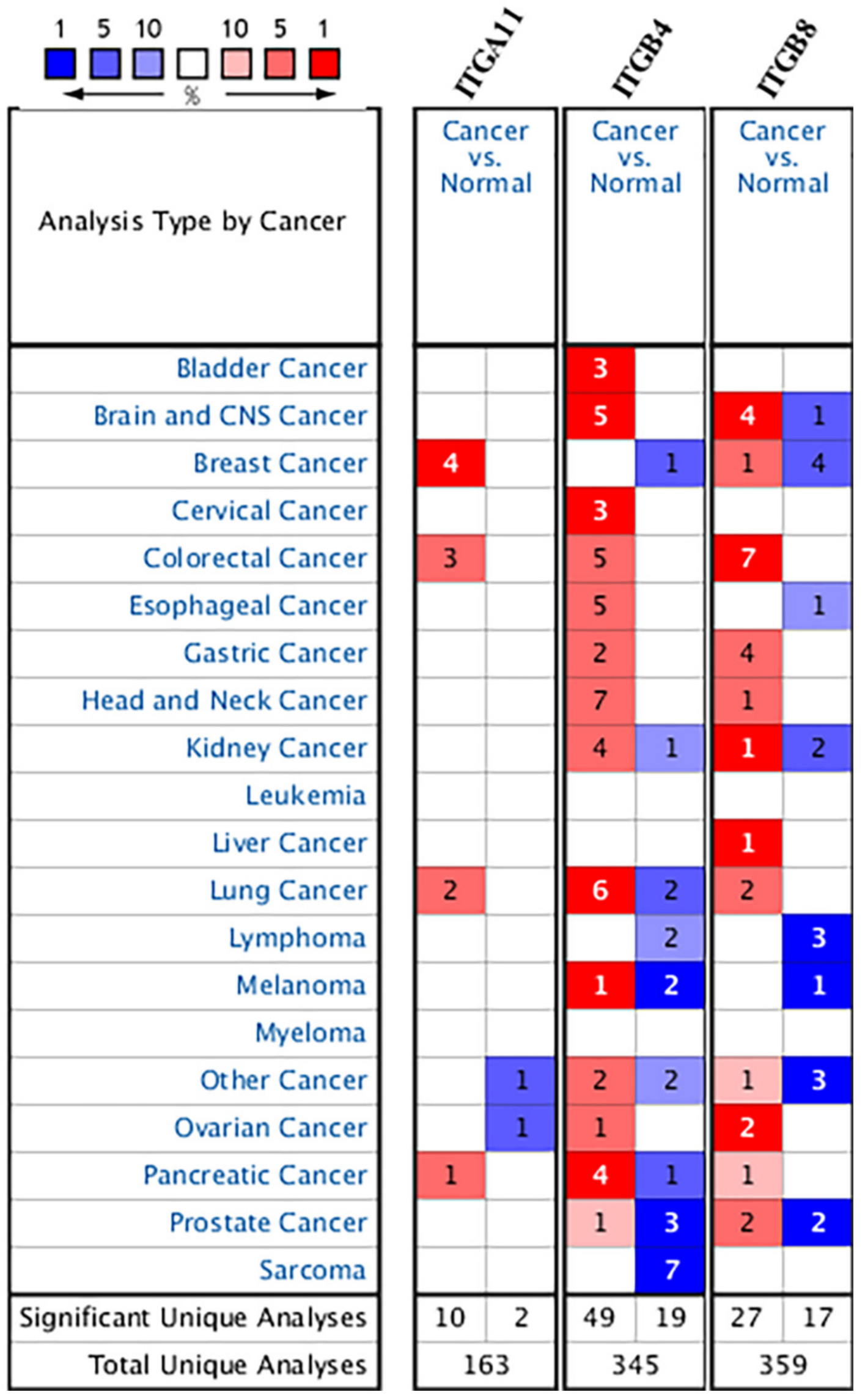


Figure 2

The expression levels of ITGA11 (A), ITGB4 (B) and ITGB8 (C) between NSCLC tissues and normal tissues in GEPIA

*Indicate that the results are statistically significant.
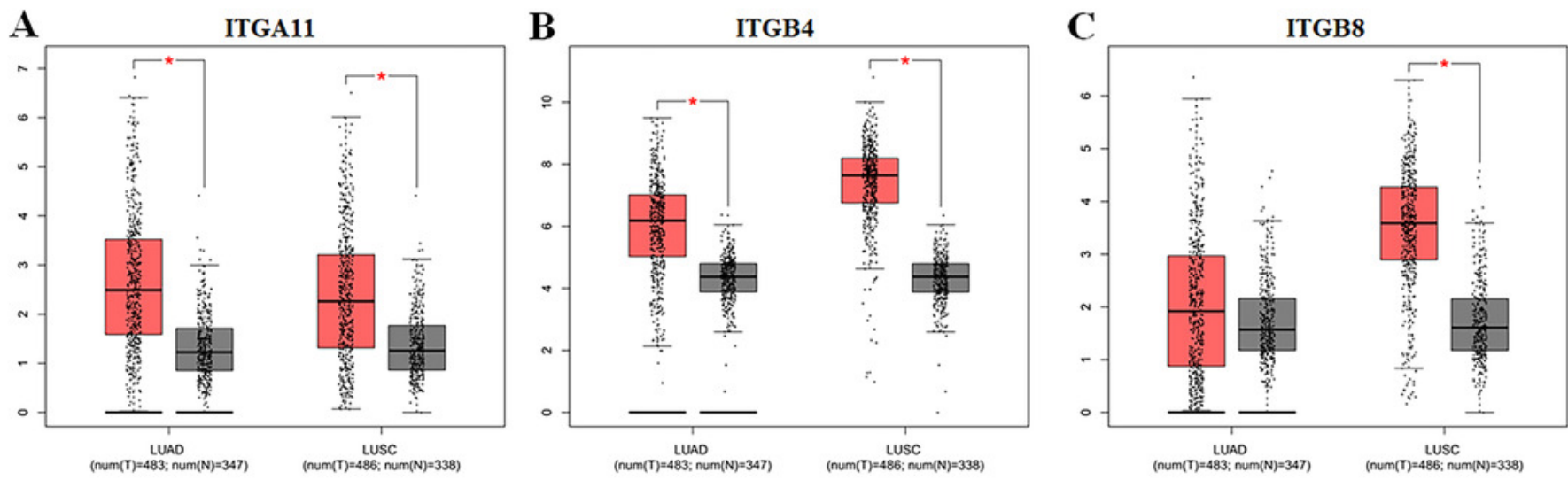


\section{Figure 3}

Immunohistochemistry analysis for ITGA11, ITGB4 and ITGB8 in NSCLC (HPA database).

(A-F) The protein expression of ITGA11 and ITGB4 were significantly higher in both LUAD and LUSC tissues compared with the normal lung, respectively. (G-I) The protein expression level of ITGB8 was significantly higher in LUSC tissues compared with the normal lung. 

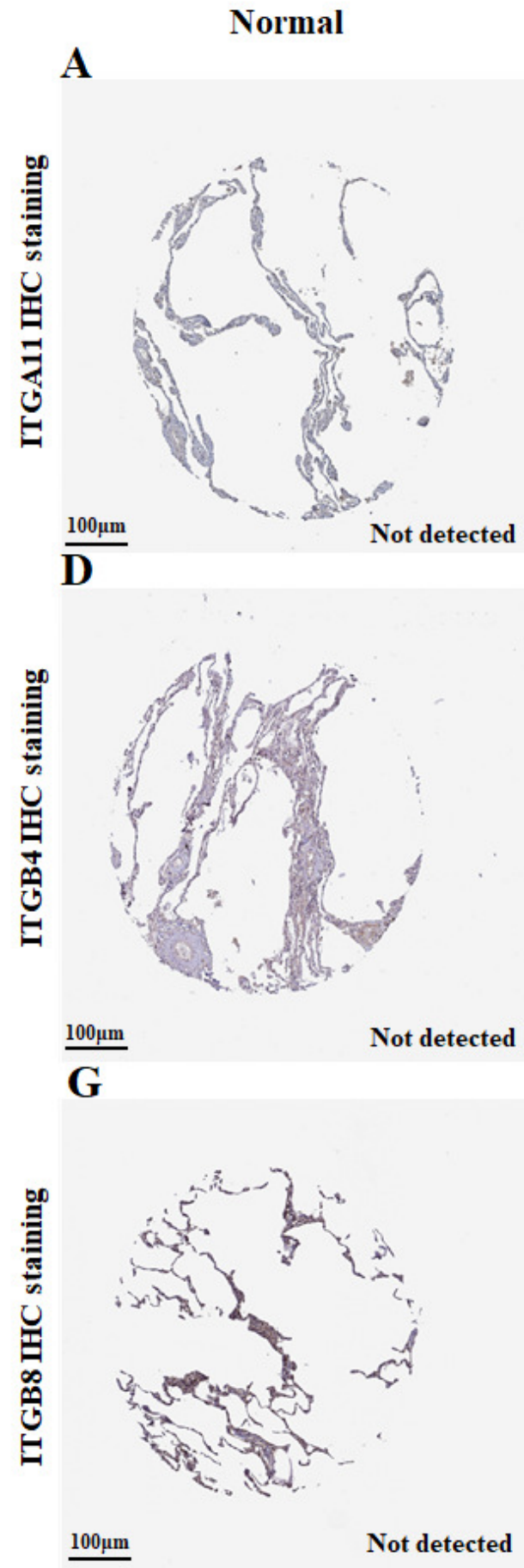

B

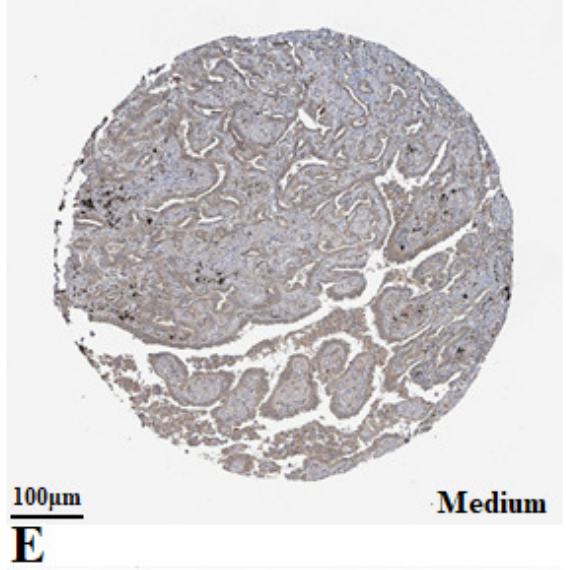

LUAD
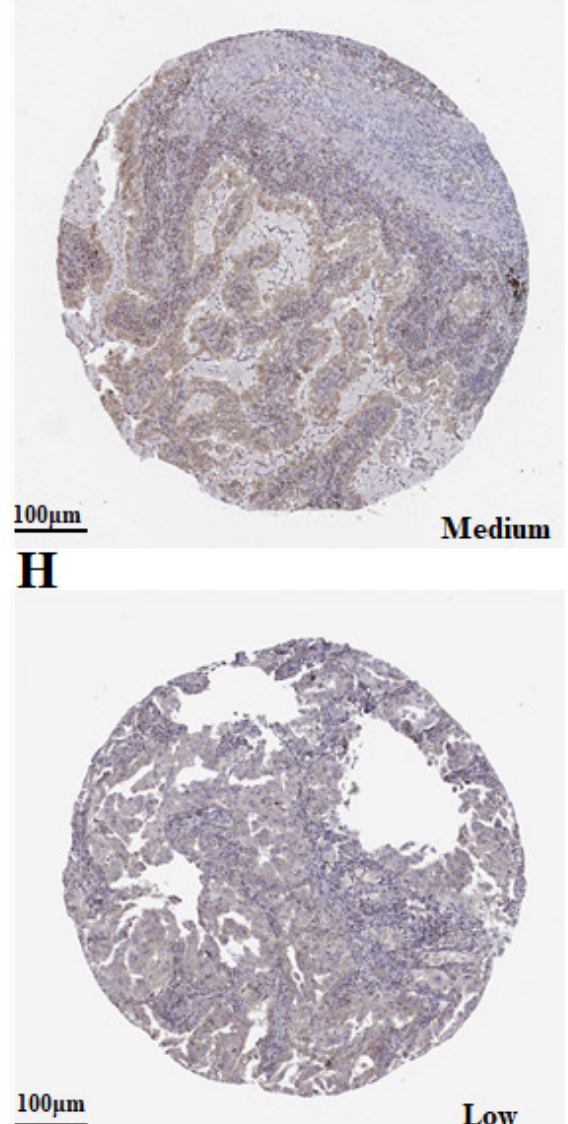

C

\section{LUSC}
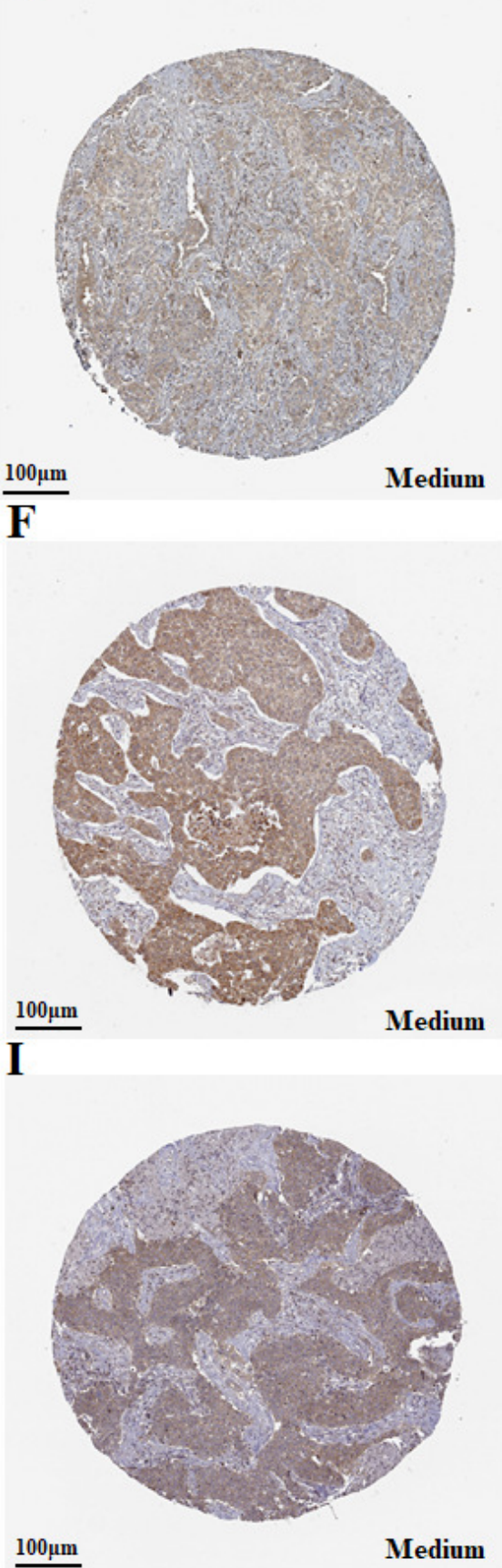
Figure 4

Meta-analysis of ITGB4 expression in LUAD tissues compared with normal controls based on GEO datasets

(A) Forest plot of SMD comparing ITGB4 expression in LUAD tissues with normal controls from the enrolled GEO datasets. (B) Sensitivity analysis of the enrolled GEO datasets. (C) The evaluation of the publication bias of the enrolled GEO datasets (Egger's test, $p=0.7759$ ). 


\begin{tabular}{|c|c|c|c|c|c|}
\hline \multirow{2}{*}{ Study } & \multicolumn{2}{|r|}{ Experimental } & \multicolumn{3}{|c|}{ Control } \\
\hline & Total & Mean SD & Total & Mean & SD \\
\hline GSE32863 & 58 & 9.831 .1867 & 58 & 8.25 & 0.4118 \\
\hline GSE63459 & 33 & $8.58 \quad 0.6444$ & 32 & 7.96 & 0.3075 \\
\hline GSE75037 & 83 & 9.811 .4067 & 83 & 7.83 & 0.6126 \\
\hline GSE 43458 & 80 & 9.261 .0511 & 30 & 8.37 & 0.3113 \\
\hline GSE10072 & 58 & $\begin{array}{lll}8.68 & 0.8618\end{array}$ & 49 & 8.01 & 0.3769 \\
\hline GSE31547 & 30 & $\begin{array}{lll}8.11 & 0.7351\end{array}$ & 20 & 7.30 & 0.2933 \\
\hline GSE7670 & 26 & 9.251 .1895 & 26 & 8.51 & 0.4168 \\
\hline GSE46539 & 92 & 12.100 .6893 & 92 & 11.88 & 0.3741 \\
\hline GSE27262 & 25 & 2.251 .6104 & 25 & 0.82 & 0.3402 \\
\hline GSE18842 & 15 & $\begin{array}{lll}7.90 & 1.2269\end{array}$ & 14 & 6.87 & 0.4595 \\
\hline GSE21933 & 11 & 12.391 .1055 & 11 & 11.40 & 0.6352 \\
\hline GSE31552 & 19 & 8.910 .8765 & 19 & 8.28 & 0.4817 \\
\hline GSE74706 & 10 & $0.64 \quad 1.5739$ & 10 & .0 .54 & 0.5668 \\
\hline GSE19188 & 45 & 0.411 .0054 & 30 & .0 .38 & 0.3312 \\
\hline GSE118370 & 6 & 9.820 .6394 & 6 & 9.34 & 0.3726 \\
\hline GSE134381 & 17 & $\begin{array}{l}7.97 \\
0.9317\end{array}$ & 17 & 7.69 & 1.3518 \\
\hline GSE103512 & 30 & 8.520 .5253 & 14 & 892 & 0.7093 \\
\hline
\end{tabular}

\section{Random effects model 638}

Heterogeneity $I^{2}=80 \%, \tau^{2}=0.2930, p<0.01$

Test for overall effect: $z=6.21(p<0.01)$

B

\section{Study}

Omitting GSE32863

Omitting GSE63459

Omitting GSE75037

Omitting GSE 43458

Omitting GSE10072

Omitting GSE31547

Omitting GSE7670

Omitting GSE46539

Omitting GSE27262

Omitting GSE18842

Omitting GSE21933

Omitting GSE 31552

Omitting GSE74706

Omitting GSE19188

Omitting GSE118370

Omitting GSE103512
Omitting GSE134381

Random effects model

\section{Standardised Mean} Difference

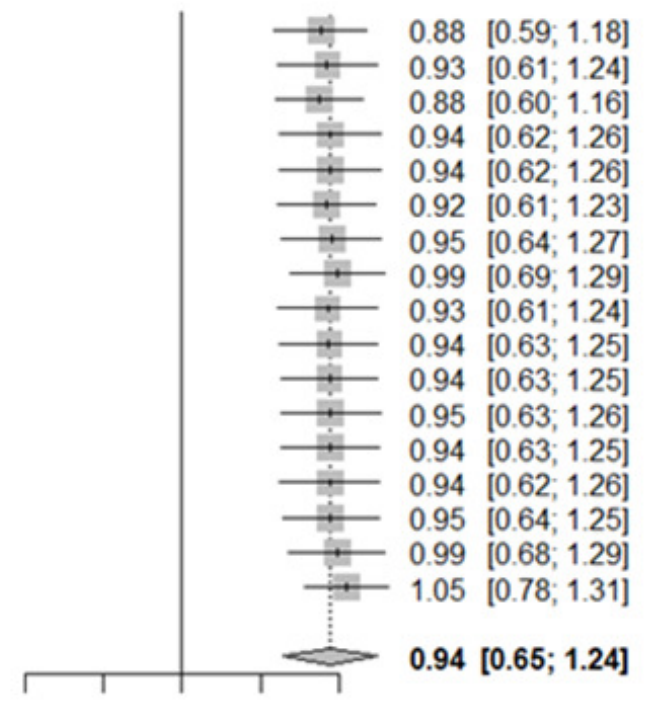

536
Standardised Mean Difference

SMD $\quad 95 \%-\mathrm{Cl}$ Weight

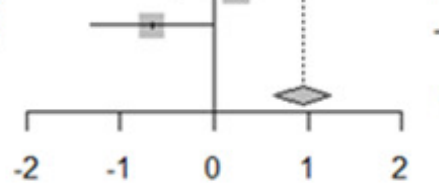

$1.76[1.33 ; 2.20] \quad 6.8 \%$

$1.20[0.67 ; 1.73] \quad 6.3 \%$

$1.82[1.45 ; 2.18] \quad 7.1 \%$

$0.97[0.53 ; 1.41] \quad 6.7 \%$

$0.98[0.58 ; 1.38] \quad 6.9 \%$

$1.32[0.69 ; 1.94] \quad 5.8 \%$

$0.81[0.25 ; 1.38] \quad 6.1 \%$

$0.39[0.10 ; 0.68] \quad 7.3 \%$

$1.21[0.60 ; 1.82] \quad 5.9 \%$

$1.07[0.28 ; 1.85] \quad 5.1 \%$

$1.05[0.15 ; 1.96] \quad 4.6 \%$

$0.86[0.20 ; 1.53] \quad 5.6 \%$

$0.95[0.02 ; 1.89] \quad 4.4 \%$

$0.98[0.49 ; 1.46] \quad 6.5 \%$

$0.84[-0.37 ; 2.04] \quad 3.4 \%$

$0.23[-0.44 ; 0.91] \quad 5.6 \%$

$.0 .67[-1.32 ;-0.02] \quad 5.7 \%$

$0.94[0.65 ; 1.24] 100.0 \%$

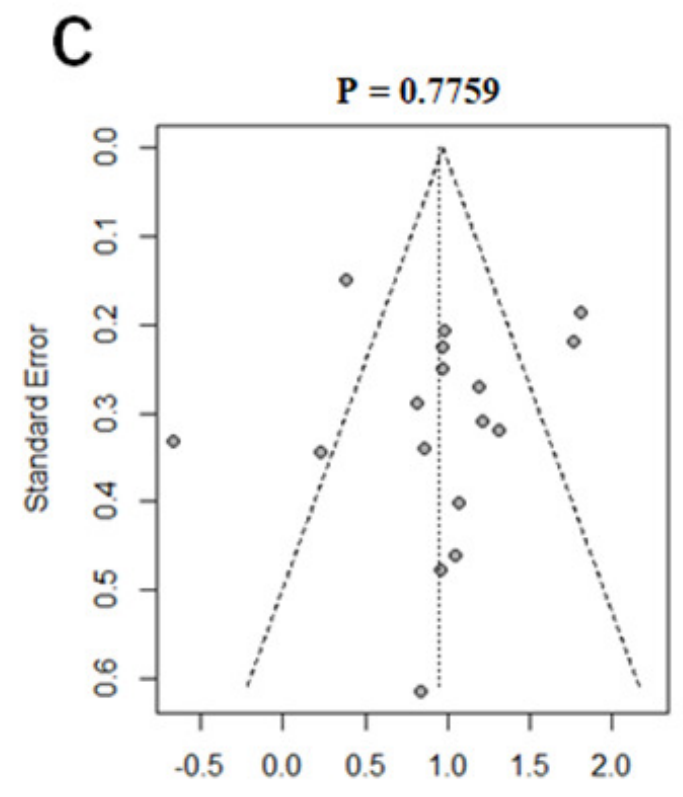

Standardised Mean Difference 
Figure 5

Kaplan-Meier survival curves of overall survival (OS) in LUAD and LUSC (GEPIA database).

Survival curves of OS based on the high and low expression of ITGA11, ITGB4 and ITGB8 in LUAD (A-C) and LUSC (D-F), respectively.
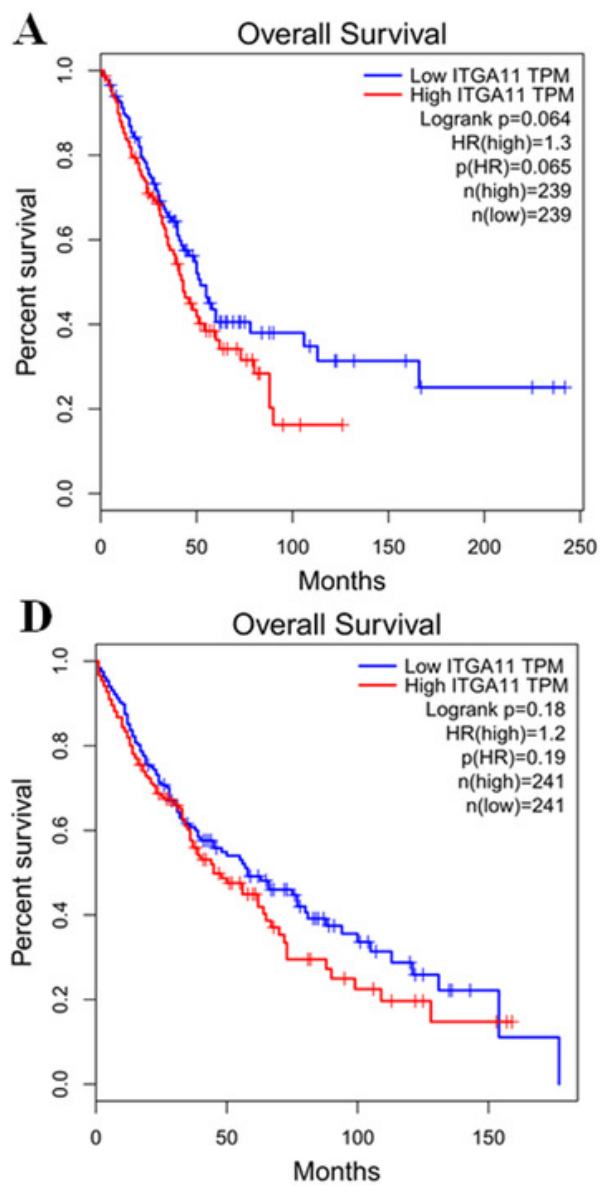

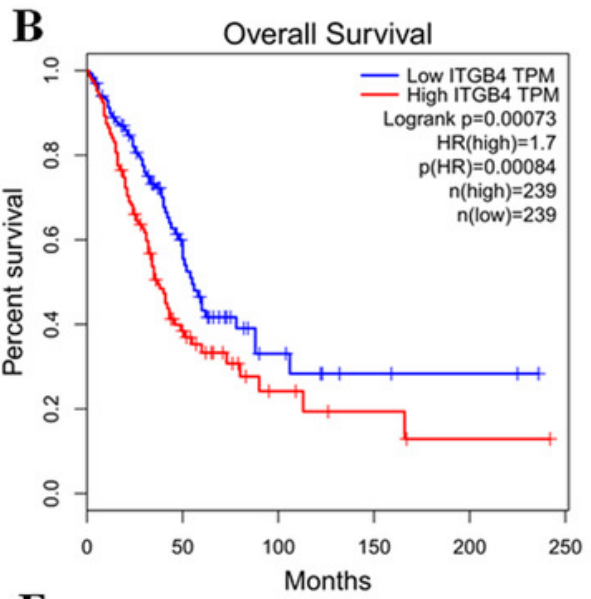

$\mathbf{E}$

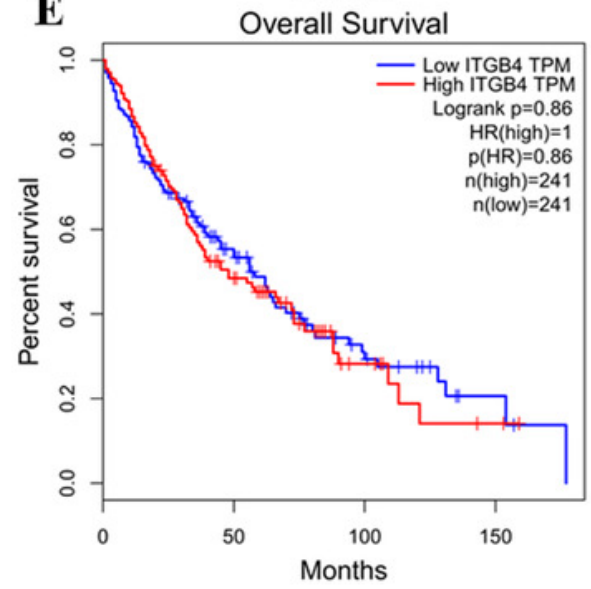

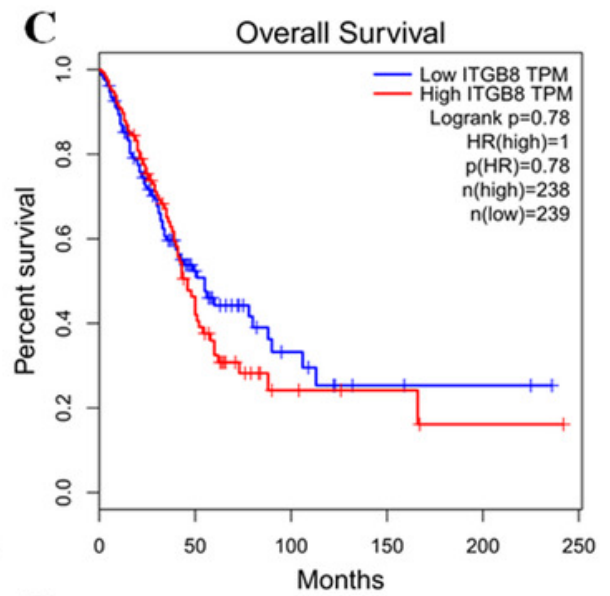

$\mathbf{F}$

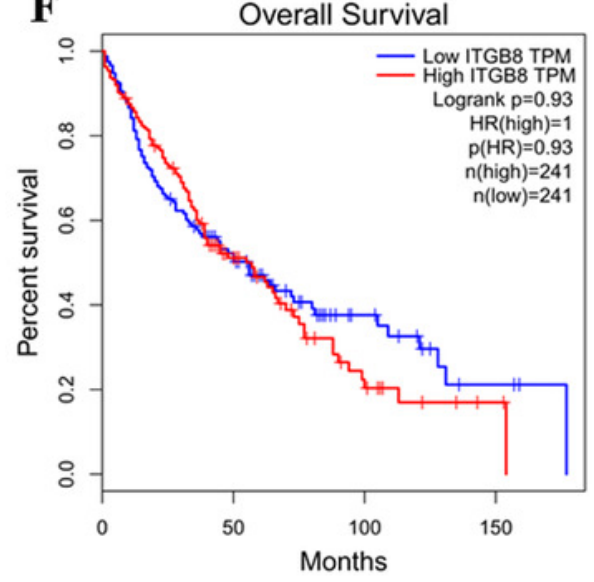


Table 2 (on next page)

Univariate and multivariate cox analysis of OS in LUAD and LUSC 


\begin{tabular}{|c|c|c|c|c|c|c|}
\hline \multirow{2}{*}{ Characteristics } & \multicolumn{3}{|c|}{ Univariate analysis } & \multicolumn{3}{|c|}{ Multivariate analysis } \\
\hline & $p$ value & HR & $95 \% \mathrm{CI}$ & $p$ value & HR & $95 \% \mathrm{CI}$ \\
\hline \multicolumn{7}{|l|}{ LUAD-OS } \\
\hline $\begin{array}{c}\text { Gender } \\
\text { Male vs. Female }\end{array}$ & 0.745 & 1.050 & $0.784-1.405$ & & & \\
\hline $\begin{array}{c}\text { Age } \\
>65 \text { vs. } \leq 65\end{array}$ & 0.229 & 1.198 & $0.892-1.610$ & & & \\
\hline $\begin{array}{l}\text { Smoking history } \\
\text { 2/3/4/5 vs. } 1\end{array}$ & 0.530 & 0.875 & $0.578-1.325$ & & & \\
\hline $\begin{array}{l}\text { Clinical stage } \\
\text { III/IV vs. I/II }\end{array}$ & 0 & 2.466 & $1.786-3.404$ & 0 & 2.329 & $1.682-3.226$ \\
\hline $\begin{array}{l}\text { ITGA11 expression } \\
\text { High vs. Low }\end{array}$ & 0.076 & 1.306 & $0.973-1.753$ & 0.361 & 1.153 & $0.849-1.566$ \\
\hline $\begin{array}{l}\text { ITGB4 expression } \\
\text { High vs. Low }\end{array}$ & 0.002 & 1.575 & $1.175-2.112$ & 0.026 & 1.417 & $1.042-1.926$ \\
\hline $\begin{array}{l}\text { ITGB8 expression } \\
\text { High vs. Low }\end{array}$ & 0.925 & 0.986 & $0.737-1.320$ & & & \\
\hline \multicolumn{7}{|l|}{ LUSC-OS } \\
\hline $\begin{array}{c}\text { Gender } \\
\text { Male vs. Female }\end{array}$ & 0.179 & 1.251 & $0.902-1.736$ & 0.177 & 1.253 & $0.903-1.739$ \\
\hline $\begin{array}{c}\text { Age } \\
>65 \text { vs. } \leq 65\end{array}$ & 0.124 & 1.253 & $0.940-1.670$ & 0.049 & 1.343 & $1.001-1.803$ \\
\hline $\begin{array}{l}\text { Smoking history } \\
\text { 2/3/4/5 vs. } 1\end{array}$ & 0.430 & 0.698 & $0.286-1.704$ & & & \\
\hline $\begin{array}{l}\text { Clinical stage } \\
\text { III/IV vs. I/II }\end{array}$ & 0.002 & 1.655 & $1.199-2.284$ & 0.002 & 1.665 & $1.204-2.301$ \\
\hline $\begin{array}{l}\text { ITGA11 expression } \\
\text { High vs. Low }\end{array}$ & 0.385 & 1.128 & $0.860-1.479$ & & & \\
\hline $\begin{array}{l}\text { ITGB4 expression } \\
\text { High vs. Low }\end{array}$ & 0.388 & 1.127 & $0.859-1.479$ & & & \\
\hline $\begin{array}{l}\text { ITGB8 expression } \\
\text { High vs. Low }\end{array}$ & 0.875 & 0.978 & $0.746-1.283$ & & & \\
\hline
\end{tabular}

1 Smoking history: 1. lifelong non-smoker; 2. current smoker; 3. current reformed smoker (for $>15$ years); 4. Current

2 reformed smoker (for $\leq 15$ years); 5. current reformed smoker (duration not specified). 